\title{
Pengembangan Pariwisata Budaya Pacuan Kuda Dalam Meningkatkan Kesejahtraan Masyarakat Desa Brang Kolong Kecamatan Plampang Kabupaten Sumbawa -NTB
}

\author{
Erwin Asidah \\ Program Studi Administrasi Bisnis Fakultas Ilmu Sosial Dan Ilmu Politik Universitas \\ Muhammadiyah Mataram Mataram
}

\begin{abstract}
Abstrak
Brang Kolong Kec. Plampang Kabupaten Sumbawa dan untuk mengetahui dampak budaya pacuan kuda dalam meningkatkan hubungan sosial masyarakat di Desa Brang Kolong Kec. Plampang Kabupaten Sumbawa. Metode yang digunakan adalah metode kualitatif dengan pendekatan etnografi. Sumber data dalam penelitian ini adalah data primer dan sumber data sekunder tentang budaya pacuan kuda dalam mempererat hubungan sosial masyarakat di Desa Brang Kolong Kecamatan Plampang Kabupaten Sumbawa.Berdasarkan hasil penelitian disimpulkan bahwa, 1) Sejarah awal munculnya budaya pacuan kuda di Desa Brang Kolong Kecamatan Plampang Kabupaten Sumbawa bermula pada saat zaman kolonial Belanda, sampai saat ini masih dipertahankan oleh masyarakat Sumbawa. Perbedaan main jaran pada zaman kolonial Belanda dengan sekarang terletak pada aturan permainan pada saat itu tidak ada, bagi siapa yang mempunyai kuda yang besar dan siap untuk diadu kecepatannya itulah yang tampil, dan arenanya pun di tanah lapang yang tidak dibuatkan arena khusus, sedangkan sekarang atribut yang digunakan oleh kuda-kuda pacu dan para joki sudah memperhatikan keselamatan, ada aturan kelas berdasarkan umur dan ukuran kuda, usia joki dan kuda pacu diberikan hiasan-hiasan. 2) Dampak budaya pacuan kuda dalam mempererat hubungan sosial masyarakat di Desa Brang Kolong Kecamatan Plampang Kabupaten Sumbawa yaitu sebagai ajang silaturahmi, persaudaraan, mengandung makna filosofi yang tinggi bagi derajat /kedudukan sosial seseorang di tengah masyarakat Sumbawa, simbol kehormatan dan kewibawaan, serta upaya untuk melestarikan budaya Sumbawa, mengembangkan pariwisata sebagai event pariwisata unggulan, ekonomi bisnis dan peternakan, dan hiburan rakyat.
\end{abstract}

Kata kunci: Budaya Pacuan Kuda, Hubungan Sosial Masyarakat

\begin{abstract}
This research tries to study the early history of horse racing culture renewal in Brang Kolong Village, Kec. Plampang Sumbawa Regency and to find out the cultural relations of horse racing in strengthening community social relations in Brang Kolong Village, Kec. Plampang Sumbawa Regency. The method used is a qualitative method using ethnography. Source of data in this study are primary data and secondary data sources on horse racing culture in strengthening community social relations in Brang Kolong Village, Plampang District, Sumbawa Regency. Based on the results of the study it was concluded that, 1) The early history of horse racing culture renewal in Brang Kolong Village, Plampang District, Sumbawa Regency began in the Dutch colonial era, until now it is still needed by the people of Sumbawa. The main difference in the Dutch colonial era and now lies in the rules of the game when there were none, for those who had big horses and were ready to be pitted at the displayed speed, and none in the field where no special arena was made, at this time the attributes used by horses - the racehorses and the jockeys are concerned about safety, there are class rules according to the age and size of the horses, the age of the jockey and the racehorses are given decorations. 2) The impact of horse racing culture in strengthening community social relations in Brang Kolong Village, Plampang Subdistrict, Sumbawa Regency is a place for friendship, brotherhood, containing a higher philosophical meaning for users in the community to preserve the culture of Sumbawa, develop leading tourism events, business economy and animal husbandry, and people's entertainment.
\end{abstract}




\section{Keywords: Horse Racing Culture, Community Social Relations}

\section{PENDAHULUAN}

Kebudayaan Indonesia begitu kaya dan beragam. Setiap daerah memiliki kebudayaan atau adat istiadat tersendiri. Hal ini merupakan aset berharga sekaligus identitas bangsa Indonesia yang wajib kita lestarikan. Kabupaten Sumbawa, merupakan salah satu daerah yang memiliki warisan budaya yang begitu kaya termasuk Kebudayaan di Kecamatan Moyo Hilir yaitu lomba kuda. Kebudayaan masyarakat Sumbawa merupakan kebudayaan turun temurun hingga saat ini. Kebudayaan tersebut masih ada hingga sekarang, seperti bahasa dan kesastraan, upacara kesenian berempuk, pacuan kuda, beserta lomba kuda dan sebagainya.

Kuda sumbawa adalah kuda lokal asli Indonesia yang merupakan persilangan kuda lokal (Sandalwood pony) dengan bangsa kuda arab atau Thotoughbred (Laili et al., 2014: 67). Masyarakat Sumbawa lebih mengenalnya dengan sebutan kuda liar Sumbawa. Kuda sumbawa tersebar hampir di seluruh Kabupaten Sumbawa, salah satunya di Kecamatan Moyo Hilir. Sistem pemeliharaan kuda di Kecamatan Moyo Hilir masih tergolong sangat sederhana dan tradisional atau dikenal dengan sistem Lar, yaitu dengan melepas ternak di padang pengembalaan sehingga pakannya berupa rumput lapangan, kuda tersebut mencari sendiri makanan yang akan di makan (Pertiwi, 2007: 37). Secara umum kuda di Kecamatan Moyo Hilir, Kabupaten Sumbawa memiliki beberapa kegunaan bagi masyarakat. Dalam bidang ekonomi, kuda Sumbawa banyak diperjual belikan hingga ke luar daerah dan dalam bidang kebudayaan kuda sumbawa memiliki fungsi salah satunya sebagai kuda pacu atau pacuan kuda, yang merupakan salah satu kegiatan kebudayaan unik yang ada di Sumbawa.

Pacuan kuda adalah event tradisional para sandro, joki dan kuda terbagus saat mulai musim tanam padi di Sumbawa dan sebagai simbol status sosial pada kebudayaan bagi masyarakat Sumbawa. Tradisi pacuan kuda tidak hanya diselenggarakan di Brang Kolong akan tetapi eksis juga di Desa Moyo Hulu, Desa Senampar, Desa Poto, Desa Lengas, Desa Batu Bangka, Desa Maronge, Desa Utan hingga desa Alas sebagai event budaya khas Sumbawa. Pacuan kuda ala Sumbawa ini diselenggarakan pada saat musim tanam padi. Ciri khas yang menarik pada pacuan kuda Sumbawa adalah adanya Lawas pacuan kuda atau yang biasa disebut dengan ngumang yang merupakan sesumbar kemenangan sebagai pemikat wanita dan penonton pacuan kuda dan merayu-rayu dengan lawas yang dikuasainya saat pacuan kuda berlangsung. Karapan kuda juga megandung makna filosofi yang tinggi bagi derajat atau pertise seseorang di tengah masyarakat Sumbawa, simbol kehormatan, kewibawaan dan derajat seseorang karena pemenang pacuan kuda di samping mendapatkan penghargaan berupa hadiah tertentu, pemenang juga akan memperoleh gelar kehormatan yang membuatnya memperoleh kedudukan sosial yang dihargai di tengah masyarakat.

Lokasi atau arena pacuan kuda adalah di arena yang telah disediakan khusus untuk mengadakan pacuan kuda di kawasan yang kering. Perlakuan pemilik kuda jargon Pacuan Kuda sama seperti perlakuan audisi Main Jaran. Kuda-kuda peserta dikumpulkan 3 hari atau 4 hari sebelum event budaya ini digelar untuk diukur tinggi dan usianya. Hal ini dimaksudkan, agar dapat ditentukan dalam kelas apa kuda-kuda tersebut dapat dilombahkan. Durasi atau lamanya event adalah ditentukan dari seberapa banyak jargon Kuda yang ikut dalam event budaya Pacuan Kuda.

Pacuan kuda ini merupakan salah satu contoh budaya dan hiburan bagi masyarakat Sumbawa yang telah turun temurun dilaksanakan. Pacuan kuda dibuat untuk membantu masyarakat Sumbawa dalam melakukan interakasi dan komunikasi dengan orang lain. Interaksi dan komunikasi yang terjadi melalui budaya pacuan kuda mengakibatkan terbentuknya kelompok sosial. Aspek menarik dari kelompok sosial adalah cara yang dilakukan dalam mengendalikan anggota-anggotanya. Hal yang penting dari 
kelompok sosial terkait tentang kekuatankekuatan yang saling berhubungan dan berkembang serta memiliki peranan dalam mengatur tindakan-tindakan anggotanya untuk mencapai tata tertib demi kebaikan kelompok. Kelompok sosial yang terbentuk dari interaksi dan komunikasi antar individu atau manusia didasarkan atas hubungan kekerabatan, usia, seks, dan terkadang atas dasar perbedaan pekerjaan atau kedudukan (Soerjono, 2013: 25).

Keanggotaan masing-masing kelompok sosial tadi memberikan kedudukan atau prestise tertentu sesuai dengan adat istiadat dan lembaga kemasyarakatan di dalam masyarakat. Namun, yang terpenting adalah keanggotaan pada kelompok sosial tidak selalu bersifat sukarela. Solidaritas merupakan suatu jenis tatanan sosial yang memandang masyarakat sebagai sebuah komponen yang berbeda dan memiliki hubungan satu sama lain. Solidaritas tersebut dibagi menjadi solidaritas mekanik dan solidaritas organik. Solidaritas mekanik terdapat dalam masyarakat pedesaan, sedangkan solidaritas organik terdapat dalam masyarakat perkotaan. Solidaritas mekanik didasarkan pada suatu kesadaran kolektif bersama yang menunjuk pada totalitas kepercayaan dan kebudayaan. Masyarakat yang ditandai dengan solidaritas mekanik menjadi satu dan padu, karena seluruh orang adalah generalis (Ritzer, 2008: 102).

Ciri-ciri atau karakteristik tersebut membuktikan bahwa masyarakat Sumbawa menganut solidaritas mekanik meskipun tidak harmonis yang dibuktikan dengan adanya sikap masyarakat Sumbawa dalam budaya pacuan kuda yang tidak memandang untung rugi dari pelaksanaan budaya pacuan kuda. Oleh sebab itu, penelitian ini menjadi hal yang sangat penting karena adanya beberapa alasan yaitu: Pertama, masyarakat Sumbawa tergolong sebagai masyarakat tradisional karena memiliki sikap-sikap yang bersifat komunal dan kolektif. Namun, jika ditinjau secara historis masyarakat Sumbawa sulit melakukan komunikasi diluar pekerjaan. Hal ini mengakibatkan masyarakat Sumbawa menjadi sulit untuk berinteraksi satu dengan lainnya, sehingga menyebabkan renggangnya hubungan diantara masyarakat Sumbawa.

Kedua, masyarakat Sumbawa merupakan masyarakat heterogen yaitu campuran dari masyarakat pendatang seperti dari suku Bima, Dompu, dan Sasak sehingga terjadi akulturasi budaya yang diakibatkan perkawinan campuran. Hal inilah yang mengakibatkan masyarakat Sumbawa menjadi agak renggang, karena mereka kurang mengenal budaya asli masyarakatnya, mereka hanya berinteraksi dengan keluarga sendiri yang sudah bercampur sehingga hubungan antara masyarakat Sumbawa menjadi kurang terjalin.

Ketiga, mayoritas masyarakat Sumbawa berprofesi sebagai petani, peternak seperti kuda, sapi dan kerbau. Para petani biasanya sibuk di ladang-ladng dan kebun-kebun yang cukup luas, biasanya mereka menetap di dekat sawah ladang mereka, jarak rumah yang satu dengan lainnya agak berjauhan. Sementara para peternak mengembakan ternak mereka di tanah lapang yang luas, sibuk mengawasi dan mengembala ternak mereka, yang memakan waktu hampir sepanjang hari. Dampak dari profesi mereka adalah kurangnya mereka bersosialisasi dengan masyarakat lain karena faktor jarak, sehingga menimbulkan kerenggangan hubungan antara masyarakat seprofesi maupun masyarakat lainnya.

Keempat, pada fase modern masyarakat Sumbawa menciptakan tradisi baru yang disebut dengan budaya merantau. Diketahui bahwa penduduk asli Sumbawa hanya sedikit yang tinggal di Sumbawa, sedangkan yang lainnya pergi untuk merantau artinya kebanyakan penduduk Sumbawa pergi merantau dan hanya sebagian kecil penduduk Sumbawa saja yang tinggal di Sumbawa. Budaya Merantau inilah yang menyebabkan terjadinya ketidakharmonisan masyarakat Sumbawa dalam berinteraksi. Namun, ketidakharmonisan ini justru dapat teratasi melalui budaya pacuan kuda. Kerenggangan hubungan ini dapat teratasi melalui budaya pacuan kuda. Budaya Pacuan Kuda menjadi Budaya yang dikenal secara luas bahkan hingga ke Mancanegara. Terakhir, budaya pacuan kuda dapat mengintegrasikan nilainilai tradisional kedalam nilai-nilai modern. 
Contoh konkritnya adalah budaya pacuan kuda yang digunakan sebagai alat untuk memperoleh kehormatan dan kebanggaan (nilai modern), dapat dibuktikan dengan pemberian semangat dan dukungan melalui pemberian hadiah-hadiah yang bernilai tinggi seperti dalam bentuk seekor hewan kuda, kendaraan bermotor, kulkas, televisi dan lain sebagainya.

Berangkat dari permasalahan di atas, maka penulis tertarik untuk mengambil judul Budaya Pacuan Kuda dalam Mempererat Hubungan Sosial Masyarakat di Desa Brang Kolong Kec. Plampang Kabupaten Sumbawa. Berdasarkan rumusan masalah di atas maka tujuan penelitian ini yaitu untuk mengetahui sejarah awal munculnya budaya pacuan kuda di Desa Brang Kolong Kec. Plampang Kabupaten Sumbawa dan dampak budaya pacuan kuda dalam mempererat hubungan sosial masyarakat di Desa Brang Kolong Kec. Plampang Kabupaten Sumbawa

\section{METODOLOGI PENELITIAN}

Penelitian ini bertujuan untuk mengungkap nilai-nilai dari dimensi budaya pacuan kuda dengan metode yang digunakan untuk mengungkap hal tersebut adalah metode kualitatif dengan pendekatan etnografi. Ada dua jenis subjek penelitian yaitu informasi kunci dan subjek penelitian biasa. Subjek penelitian kunci adalah informasi utama yaitu masyarakat Desa Brang Kolong Kec. Plampang Kabupaten Sumbawa yang berjumlah 10 orang, sedangkan yang menjadi subjek penelitian biasanya adalah tokoh agama, tokoh masyarakat, pelaku/ peternak pacuan kuda dan panitian pacuan kuda di Desa Brang Kolong Kec. Plampang Kabupaten Sumbawa sebanyak 5 orang. Jenis data pada penelitian ini adalah data kualitatif, dengan dua sumber data yaitu data primer dalam hal ini yang dimintai keterangan adalah masyarakat yang memiliki pacuan kuda, tokoh masyarakat, pemuda, kades, kadus di Kecamatan Moyo Hilir Kabupaten Sumbawa dan data skunder yang digunakan dalam penelitian ini meliputi buku-buku, internet, dokumen resmi, dan makalah yang berhubungan dengan budaya pacuan kuda dan hubungan sosial masyarakat. Metode pengumpulan data yang digunakan dalam penelitian ini yaitu observasi, dan interview (wawancara), dokumentasi. Analisis dengan beberapa langkah reduksi data yaitu reduksi data, penyajian data, penyajian data dan penarikan kesimpulan.

\section{HASIL PENELITIAN DAN PEMBAHASAN}

\section{Sejarah Awal Munculnya Budaya Pacuan Kuda di Desa Brang Kolong Kecamatan Plampang Kabupaten Sumbawa}

Karapan kuda atau lebih dikenal dengan istilah "maen jaran atau pacuan kuda" oleh masyarakat Sumbawa merupakan permainan yang sangat digemari oleh penduduk Kabupaten Sumbawa, selain menjadi atraksi hiburan, juga menjadi ajang meningkatkan harga jual kuda, karena kuda yang biasanya menjadi pemenang harga jualnya tinggi. Harganya bisa mencapai ratusan juta rupiah.

Sejarah perkembangan permainan ini bermula pada saat zaman kolonial Belanda, sampai saat ini masih dipertahankan oleh masyarakat Sumbawa. Perbedaan main jaran pada zaman kolonial Belanda dengan sekarang, aturan permainan pada saat itu tidak ada, bagi siapa yang mempunyai kuda yang besar dan siap untuk diadu kecepatannya itulah yang tampil, dan arenanya pun di tanah lapang yang tidak dibuatkan arena khusus. Sesuai dengan perkembangan zaman, main jaranpun ikut berkembang. Hal ini masih kita lihat sampai sekarang yang dilakukan oleh masyarakat Sumbawa. Dilihat dari atribut yang digunakan oleh kuda-kuda pacu dan para joki sudah memperhatikan keselamatan. Kuda pacu diberikan hiasan-hiasan yang terbuat benang woll dan bahan lainnya, berikut disebutkan beberapa atribut yang digunakan oleh kuda pacu.

1. Jombe atribut yang terbuat tali (benang woll) yang ditempelkan berbagai macam pernak pernik dan dipasang di muka dan leher kuda.

2. Tali kancing merupakan tali yang diikat dan dipasang di dalam mulut kuda dan digunakan pada saat pelepasan. 
3. Kili merupakan kawat yang dibuat berbentuk angka delapan sebagai penyambung tali pengendali dengan rantai yang ada dipasang di mulut kuda.

4. Lapek merupakan alas tempat duduk joki yang diletakkan pada punggung kuda dan terbuat dari alang-alang dan atau daun pisang kering.

Begitu halnya dengan atribut yang digunakan oleh joki, juga diperhatikan dengan tujuan untuk menjaga keselamatan para joki. Berikut disebutkan beberapa atribut yang digunakan oleh para joki.

1. Helem digunakan sebagai pelindung kepala dan berfungsi sebagai untuk mengurangi cidera dari joki apabila terjatuh.

2. Baju kaos berlengan panjang dan celana panjang.

3. Ketopong digunakn sebagai sarung kepala digunakan sebelum memakai helem.

4. Cambuk biasanya terbuat dari kayu rotan.

5. Baju ban (baju rompi) yang memiliki nomor sebagai nomor urut kuda.

Selain perkembangan atribut yang digunakan oleh para joki, peraturan main jaranpun mengalami perubahan. Zaman dahulu peraturan main jaran tidak terlau ketat, namun sekarang peraturan-peraturan tersebut sangat ketat. Dari arena pacuan sampai aturan mainnya sangat diperhatikan. Aturan-aturan yang dterapkan dalam permain/olahraga main jaran. Mulai dari kuda, kuda yang digunakan harus disesuaikan dengan kelasnya masingmasing. Berikut beberapa klasifikasi kuda pacu dalam main jaran Sumbawa.

1. Teka saru yaitu kelas untuk kuda pemula dan baru pertama kali melakukan perlombaan.

2. Teka pas untuk kelas yang telah mengikuti perlombaan sebanyak 2-3 kali.

3. Teka A untuk kuda sudah berpengalaman yang tingginya $117 \mathrm{~cm}$ sampai dengan 120 $\mathrm{cm}$.

4. Teka B untuk kuda yang memiliki tinggi $121 \mathrm{~cm}$ ke atas.

5. Kelas OA untuk kuda yang lawas sudah berpengalaman dan telah nyepo (giginya telah copot sebanyak 4 buah) dan tingginya $126 \mathrm{~cm}$
6. Kelas OB untuk kelas di atas OA yang memiliki tinggi $127 \mathrm{~cm}$ sampai dengan 129 $\mathrm{cm}$.

7. Harapan untuk kuda yang memiliki tinggi $129 \mathrm{~cm}$ ke atas dan telah nyepo (giginya telah copot sebanyak 4 buah).

8. Tunas untuk kuda yang memiliki tinggi $129 \mathrm{~cm}$ ke atas dan gigi taringnya telah tumbuh.

9. Kelas dewasa.

Adapun teknik yang harus diikuti oleh para pemain dalam mengikuti main jaran. Kuda yang tampil dalam pertandingan harus melakukan registrasi dan sekaligus mengambil nomor ban (kotak pelepasan). Para joki mengirng kudanya menuju juri yang bertugas memeriksa kuda dan kesiapan joki untuk menjaga adanya kecurangan dalam perlombaan. Kuda dan joki yang telah mengalami pemeriksaan langsung menuju kotak pelepasan sesuai dengan nomor urut ban (kotak pelepasan) yang didapat dari registrasi. Kuda dan joki bersiap untuk berlari sekencangnya setelah mendengar suara peluit dari juri garis. Seperti halnya main bola, main jaran juga menggunakan sistem gugur dalam menentukan sang juara. Pada babak pertama dinamakan babak guger (gugur) pada babak ini kuda berusaha untuk menuju babak penentu hingga sampai babak final.

Keunikan lain yang ada pada perlombaan karapan atau pacuan kuda atau main jaran ini adalah adanya lawas. Lawas ini sama halnya pada lomba karapan kerbau atau yang biasa disebut dengan ngumang merupakan sesumbar kemenangan sebagai pemikat wanita penonton karapan kuda atau kerbau dan merayu-rayu dengan lawas yang dikuasainya saat karapan kuda berlangsung. Dalam lawas terkandung berbagai nilai dan pesan moral yang merupakan warisan budaya tanah Sumbawa. Untuk memahami isi atau maksud dari diperlukan kemampuan berbahasa Sumbawa, mengingat bahasa lawas adalah bahasa daerah Sumbawa yang menggunakan gaya bahasa yang sarat akan kata-kata yang bermakna denotasi. Karapan kuda adalah event tradisional para sandro, Joki dan Kuda terbagus saat tiba musim tanam Sumbawa. Tradisi Barapan Kuda tidak hanya diselenggarakan di Desa Brang Kolong 
Kecamatan Plampang, akan tetapi eksis juga di Desa Pamulung, Moyo Hulu, Desa Senampar, Desa Poto, Desa Lengas, Desa Batu Bangka, Desa Maronge, Desa Utan hingga desa Alas sebagai event budaya khas Sumbawa.

Jadi, Lawas karapan kuda adalah lantunan syair pantun daerah Sumbawa yang dilakukan diantara terikan kemenangan sang joki, saat kudanya mampu menyentuh dan menjatuhkan tanpa sedikitpun terjatuh dari kareng-nya.

\section{Dampak Budaya Pacuan Kuda Dalam Mempererat Hubungan Sosial Masyarakat di Desa Brang Kolong Kecamatan Plampang Kabupaten Sumbawa}

Tradisi balapan unik di Sumbawa selanjutnya adalah main jaran (pacuan kuda). Setiap kali diadakan, acara pacu kuda akan diramaikan oleh anak-anak, remaja, dan orang tua. Pacuan kuda skala besar biasanya dilakukan dua kali setahun dan akan diikuti oleh joki dari seluruh Indonesia bagian tengahtimur mulai dari Lombok, Bima, sampai Sumba. Sementara, pacuan kuda skala kecil hanya dilakukan di daerah saja. Hari-harinya pun berubah-ubah tak menentu. Di Kabupaten Sumbawa, main jaran diselenggarakan di Lapangan Angin Laut, Desa Penyaring, Moyo Utara.

Tujuan utama kegiatan ini sebagai upaya atau ajang silaturahmi antar masyarakat Sumbawa setiap dua kali setahun, ikatan persaudaraan serta upaya untuk melestarikan budaya Sumbawa, mengembangkan pariwisata sebagai event pariwisata unggulan, ekonomi bisnis dan peternakan, dan hiburan rakyat, melestarikan budaya Sumbawa, mengembangkan pariwisata dan peternakan. Event ini juga dilaksanakan untuk hiburan rakyat. Sebab selain siang hari menyaksikan puluhan bahkan ratusan kuda bertarung, malam harinya mereka menikmati lomba karaoke dan qasidah rabana.

Event pacu kuda besar biasanya berhadiah uang, kuda, sapi, televisi, kulkas, bahkan motor - tergantung sponsor. Sebelum mengikuti lomba, kuda-kuda harus dites kesehatannya oleh tim kesehatan yang disediakan panitia. Kuda akan dimandikan dan didandani oleh pemiliknya, lalu disiram dengan air cabe di bagian pantat supaya larinya makin kencang. Pacuan akan dimenangkan oleh kuda yang tercepat di tiap kelas. Yang kalah, seperti karapan kuda, akan langsung tersingkir.

Di event pacuan kuda trasional ini setiap hari ribuan orang akan datang, menghabiskan siang hari dengan pacuan kuda, dan malam hari dengan hiburan di lokasi setempat dengan nyanyian dan acara lain yang sangat memikat. Ratusan bahkan ribuan orang yang datang dari berbagai daerah di Sumbawa, baik sebagai peserta maupun penonton adalah turis-turis local yang sangat penting dibandingkan turis asing. Dapat dibayangkan turis lokal yang memiliki dampak ekonomi sangat besar tersebut oleh Pemda dapat disuguhi tarian dan berbagai atraksi daerah ini yang menawan sehingga nama Sumbawa menjadi mampis. Benar-benar event ini berdampak ekonomi, karena merupakan pariwisata yang hakiki yang harus disambut dengan hangat.

Para peserta yang ikut serta dalam lomba pacuan kuda ini, akan menurunkan kuda terbaiknya. Kuda lokal yang sudah diberi nama itu akan turun menurut kelasnya. Mengenai persiapan, biasanya dalam dua minggu para pemilik kuda akan melatih kudanya seperti latihan berenang di Pantai, ditambah asupan gizi berupa susu dicampur air gula merah dan gula baso dari Lamenta Empang, serta Asam Jawa. Para pemiliki kuda berharap dapat mengulang sukses pada perlombaan pacuan kuda dengan kuda miliknya yang sukses merebut trophy di event tersebut. Target minimalnya berharap masuk final atau berlaga sampai di hari akhir.

Untuk diketahui lomba pacuan kuda biasahnya akan memperebutkan berbagai hadiah yang cukup bergengsi seperti sepeda motor, sapi, kulkas, televisi berwarna dan uang tunai puluhan bahkan ratusan juta rupiah untuk juara umum.

Adapun dampak posotif dari pacuan kuda atau main jaran ini sebagai berikut:

1) Karapan kuda atau main jaran sebagai permainan sekaligus olah raga yang sebagai mana pernan dan fungsi olah raga lainya yaitu untuk menyehatkan tubuh.

2) Bakat dan hobi para pelaku main jaran dapat ekspolarisasai dengan adanya kegiatan rutin main jaran satehun sekali. 
3) Dengan adanya main jaran ini masyarakat Sumbawa bisa terhibur.

4) Wujud kebudayaan main jaran ini merupakan sebuah kebudayaan yang dilaksanakan oleh masyarakat Sumbawa dua kali setahun. Sehingga turis lokal dan turis manca negara ikut serta menonton acara ini. Dengan adanya kedatangan tauris ini dapat mengahsilkan devisa daerah.

5) Pacuan kuda sebagai simbol status sosial yaitu memiliki derajat sosial seseorang di tengah masyarakat Sumbawa, simbol kehormatan, kewibawaan dan derajat seseorang karena pemenang pacuan kuda di samping mendapatkan penghargaan berupa hadiah tertentu, pemenang juga akan memperoleh gelar kehormatan yang membuatnya memperoleh kedudukan sosial yang dihargai di tengah masyarakat Adapun dampak negatif dari pacuan kuda atau main jaran sebagai berikut:

1) Karapan kuda atau main jaran merupakan permainan sekaligus olah raga yang melatih adrenalin para pemainnya. Terkadang permaianan ini dapat menimbulkan cidra yang sangat serius bahkan mengakibatkan kematian akibat kecelakaan, meskipun atribut yang digunakan saat sekatang sudah memperhatikan keselamatan para jokinya.

2) Main jaran merupakan tempat acara hiburan yang mempertontonkan adu kecepatan antarkuda pacu. Keadaan ini dapat menjadi ajang perjudian oleh sebagian orang.

3) Di lihat dari joki dari main jaran ini merupak anak-anak yang usiannya berkisar 8-15 tahun, terkadang ketika mengikuti acaranya ini mereka lebih mementing acara main jaran dari pada sekolahnya. Sehingga acara ini dapat mengganggu aktifitas belajar para joki tersebut.

\section{Simpulan}

Berdasarkan hasil penelitian maka dapat ditarik kesimpulan yaitu sebagai berikut:
1. Sejarah awal munculnya budaya pacuan kuda di Desa Brang Kolong Kecamatan Plampang Kabupaten Sumbawa yaitu bermula pada saat zaman kolonial Belanda, sampai saat ini masih dipertahankan oleh masyarakat Sumbawa. Perbedaan main jaran pada zaman kolonial Belanda dengan sekarang, aturan permainan pada saat itu tidak ada, bagi siapa yang mempunyai kuda yang besar dan siap untuk diadu kecepatannya itulah yang tampil, dan arenanya pun di tanah lapang yang tidak dibuatkan arena khusus. Begitu halnya dengan atribut-atribut yang digunkan oleh kuda maupun para joki sangat sederhana yang masih belum memperhatikan keselamatan kuda dan jokinya. Sedangkan sekaragn atribut yang digunakan oleh kudakuda pacu dan para joki sudah memperhatikan keselamatan, ada aturan kelas berdasarkan umur dan ukuran kuda, usia joki dan kuda pacu diberikan hiasanhiasan yang terbuat benang dari woll dan bahan lainnya.

2. Dampak budaya pacuan kuda dalam mempererat hubungan sosial masyarakat di Desa Brang Kolong Kecamatan Plampang Kabupaten Sumbawa yaitu sebagai ajang silaturahmi, persaudaraan, mengandung makna filosofi yang tinggi bagi derajat /kedudukan sosial seseorang di tengah masyarakat Sumbawa, simbol kehormatan dan kewibawaan serta upaya untuk melestarikan budaya Sumbawa, mengembangkan pariwisata sebagai event pariwisata unggulan, ekonomi bisnis dan peternakan, dan hiburan rakyat.

\section{Saran}

Berdasarkan kesimpulan di ats, beberapa saran dapat disampaikan sebagai berikut:

1. Bagi pemerintah, bahwa hasil penelitian ini sebagai bahan informasi dalam upaya memberikan penyuluhan dan pembinaan kepada masyarakat akan pentingnya budaya pacuan kuda, namun juga harus memperhatikan sisi psikologi para joki yang masih berusia sekolah agar lebih memperhatikan pendidikan di samping pengembangan budaya itu sendiri. 
2. Bagi peneliti sendiri hasil penelitian ini dapat dipakai untuk menambah pengetahuan baru tentang budaya pacuan kuda.

3. Bagi masyarakat, perlu diadakannya pembinaan dalam melestarikan budaya karapan kuda ini, terutama dalam memilih joki dengan memperhatikan usia, pendidikan dan keselamatan mereka, mengingat usia mereka merupakan usia sekolah yang sangat memerlukan pendidikan.

\section{DAFTAR PUSTAKA}

Departemen Pendidikan dan Kebudayaan. 2003. Kamus Besar Bahasa Indonesia. Jakarta: Balai Pustaka

Dinas Kebudayaan Kabupaten Sumbawa. 2010. Kebudayaan Masyarakat Sumbawa. Diknas Kabupaten Sumbawa

Endraswara. 2006. Metode, Teori, Teknik, Penelitian Kebudayaan: Ideologi, Epistemologi dan Aplikasi. Yogyakarta. Pustaka Widyatama

Hasan, 2010. Metode Penelitian. Jakarta: Balai Pustaka.

Iskandar dkk. 2003. Kuda. Yayasan Pamulang, Jakarta.

Iskandar dkk.2003. Karapan Kuda. Jakarta: PT. Books Komodo

Koentjaraningrat. 2010. Pengantar Ilmu Antropologi. Jakarta: Rineka Cipta

Listiyani. 2011. Makna Budaya Dalam Komunikasi Antar Budaya. Yogyakarta: LKIS

Mangaukang. 2003. Ilmu Kemajiran Ternak. Edisi Pertama. IPB, Bogor

Moleong Lexy. 2014. Metode Penelitian Kualitatif, Bandung: PT. Rosdakarya Persada.

Sulaeman. 2010. Ilmu Budaya Dasar: Suatu Pengantar. Bandung: PT Eresco

Susanto. 2011. Puspawarna Seni Tradisi dalam Perubahan Sosial-Budaya. Yogyakarta: Kanwa Publisher 